\title{
Cross-age peer tutoring in a technology-enhanced STEAM project at a lower secondary school
}

\author{
Satu Tenhovirta ${ }^{1} \cdot$ Tiina Korhonen $^{2} \cdot$ Pirita Seitamaa-Hakkarainen $^{1}$ (D) . \\ Kai Hakkarainen ${ }^{1}$
}

Accepted: 8 April 2021 / Published online: 24 April 2021

(c) The Author(s) 2021

\begin{abstract}
The present investigation examined cross-age peer tutoring in the context of organising a technology-enhanced STEAM project aimed at bringing elements of maker culture to a lower secondary school. We examined how 8th graders tutored 7th graders in programming skills. The participants were peer tutors $(n=15)$ studying in a technology-oriented class, along with their teachers (5) and the researchers (2). By interviewing the tutors, we studied skills that the tutors had experienced as being essential to overcoming the challenges encountered. To trace the tutors' social support network and the sharing of expertise, we asked the participants to draw a personal social network map. Three key tutors were identified, whose centrality in the network was socially validated by the number of peer tutors seeking their advice. Two case studies of key tutors' learning networks were carried out. The findings revealed that the tutors needed versatile technological, social, pedagogical, and reflective know-how in the project. It is concluded that cross-age peer tutoring provides significant support for implementing practices of making and STEAM education at school.
\end{abstract}

Keywords Advice size $\cdot$ Co-invention $\cdot$ Cognitive centrality $\cdot$ Cross-age tutoring $\cdot$ Makercentred learning $\cdot \mathrm{STEAM} \cdot$ Peer tutoring

Pirita Seitamaa-Hakkarainen

pirita.seitamaa-hakkarainen@helsinki.fi

Satu Tenhovirta

satu.tenhovirta@gmail.com

Tiina Korhonen

tiina.korhonen@helsinki.fi

Kai Hakkarainen

kai.hakkarainen@helsinki.fi

1 Faculty of Educational Sciences, University of Helsinki, Helsinki, Finland

2 Innokas Network, Faculty of Educational Sciences, University of Helsinki, Helsinki, Finland 


\section{Introduction}

The purpose of the present investigation was to examine cross-age peer tutoring in the context of maker-centred learning (Clapp et al., 2016) at a lower secondary school in the capital region of Finland. By cross-age peer tutoring, we refer to engaging technologically proficient older students in supporting their younger peers' collaborative making processes. Together with traditional tools, emerging digital fabrication technologies enable the engagement of young students in inventing, designing, and making complex artefacts, sparking engineering and technological challenges. Educational maker activities can be productively connected with integrated Science, Technology, Engineering, Arts, and Mathematics (STEAM) studies, which also play a central role in the Finnish curriculum. Making projects provide multi-faceted technological (tools) and social (community) resources that enable young people to participate in socially creative practices of invention (Blikstein, 2013; Clapp et al., 2016; Halverson \& Sheridan, 2014; Hatch, 2014; Petrich et al., 2013; Riikonen et al., 2020), which appear crucial for cultivating 21 st century competences (Binkley et al., 2012). Due to drastic changes in society and working life that digitalisation is bringing about, educational institutions have had to renew their practices of learning and teaching in terms of engaging students in project-based structured activities that involve the creative use of sociodigital technologies. This concept refers to the recently emerged integrated system of mobile and wireless technologies, social media, digital fabrication tools, and internet (Hakkarainen et al., 2015).

Investigators are concerned about the creative participation gap (Jenkins et al., 2006) in terms of only advantaged students having access to the creative and academic practices of using digital technologies (Barron, 2004). Many students who have developed considerable digital competences through informal activity feel that their out-of-school digital creative competences are not at all acknowledged at school; consequently, they may become increasingly alienated and cynical at school and lose their motivation (Hietajärvi et al., 2020). Thus, education systems should embrace young people's sociodigital competences learned outside classrooms and provide legitimate contexts for their productive use, nurture, and refinement, as emphasised by the connected learning framework (Ito et al., 2013). As some students are already skilful, and often more so than their teachers, authorities must begin to capitalise on peer-to-peer social learning resources, such as cross-age peer tutoring, when initiating challenging STEAM projects in schools. Peer tutoring is not a new approach, and its importance has already been mentioned, for instance, in the newest Finnish curriculum (NCCBE, 2014).

Nevertheless, the prevailing educational practices have not yet integrated the systematic use of cross-age peer tutoring in different school subjects, such as design and technology education. Cross-age peer tutoring involves engaging older students (one grade above) in systematically assisting and helping their younger peers (lower graders) in pursuing longstanding maker-centred learning projects. It follows that cross-age peer tutoring does not merely mean collaborative learning in mixed-age groups, but also provides older technologically proficient students with a legitimate role in tutoring young peers' efforts of designing, inventing, and making artefacts (Duran \& Topping, 2017, p. 66). The present study focused on developing a cross-age peer tutoring system by training 7 th graders to take a productive part in collaborative maker-centred learning through assisting 8th graders (Clapp et al., 2016). Because teachers are often not as fluent technology users and only have limited time for refining their digital competences, peer tutors may play a crucial role in integrating the advanced use of digital technologies with school practices. Cross-age 
peer tutoring has not yet been extensively studied in the emerging context of maker-centred learning in education. The present investigation contributes to both filling the research gap and sharing experiences of developing associated tutoring pedagogies and practices relevant for improving STEAM education.

\section{Maker-centred learning cultivating creativity in schools}

The term maker-centred learning has been developed to define learning processes where the aim is to foster creativity through intensive learning by making processes within a shared interactive space (Clapp et al., 2016). For learning to function productively in the emerging innovation-driven knowledge society, young people have to be socialised, early on, to innovative practices working with knowledge, media, and artefacts (Hakkarainen, 2009). The present investigators examine such practices in terms of knowledge-creating learning, which involves collaborative efforts of advancing shared tangible objects of enquiry (Paavola \& Hakkarainen, 2014; Ritella \& Hakkarainen, 2012). Maker-centred learning is based on the idea of constructionism: Active hands-on and participatory learning designed to help pupils to engage in a creative process under the guidance of instructors. Although many investigators from Piaget to Papert (1980) have emphasised the importance of learning by constructing and inventing artefacts, the present digital fabrication technology allows practices of a "maker culture" to be brought to schools in terms of feasible projects with hitherto unforeseen complexity and intellectual challenges (Papavlasopoulou et al., 2017; Schad \& Jones, 2020). The present study focused on bringing elements of a maker culture to a school in terms of engaging teams of 7 th grade students in pursuing co-invention projects that called for the use of digital fabrication and traditional technologies in designing and making artefacts (Blikstein, 2013; Riikonen et al., 2020). Thus, maker-centred learning has sparked interest in primary and secondary education due to its emphasis on STEAM-related themes (Petrich et al., 2013; Hsu et al., 2017). By relying on visions of integrated STEAM projects as well as on the extensive Finnish tradition of craft and technology education (Riikonen et al., 2020), the present investigators have been working on integrating longitudinal maker-centred projects as an integral part of elementary and secondary education.

Towards that end, it is important that the newest Finnish National Core Curriculum for Basic Education (NCCBE, 2014) involves phenomenon-based, i.e. integrative thematic, studies that provide opportunities to engage students in cross-disciplinary maker projects (Silander et al., in press). Such projects focus on open-ended challenges and complex problems, the successful investigation of which usually requires integrating several school subjects, including craft education. Rather than relying on linear pedagogy characterised by pre-given knowledge, tasks, stages, and outcomes, such maker-centred projects rely on nonlinear pedagogy in terms of pursuing open-ended innovation challenges, emerging objects, unanticipated tasks, indeterminate stages, and unforeseen outcomes (Härkki et al., 2020). It follows that the projects may require multi-faceted and unforeseen skills when using digital instruments, such as coding platforms, microprocessors, robotics, e-textiles, and 3D printing. The digital methods and practices necessary for completing a team project may not only be new for students but also for many teachers. Because the orchestration of such projects is extremely challenging for teachers, we engage multi-disciplinary teams of teachers in organising them (Härkki et al., 2020). Practices of cross-age peer tutoring provide significant support for teachers, allow them to focus on flexible pedagogic 
orchestration, and prevent them from becoming overwhelmed by the technological challenges of the diverse digital instruments employed.

Science and technology studies indicate that rather than arising from mere logical arguments, knowledge creation is distributed and stretched over scientific concepts and instruments, methods, and procedures; embodied arrangements of laboratory spaces; and networks of peers and experts (Knorr Cetina, 1999; Nersessian, 2006; Ritella \& Hakkarainen, 2012). Accordingly, the actionable implementation of STEAM practices and maker-centred learning requires special learning spaces called makerspaces (Papavlasopoulouet et al., 2017; Schad \& Jones, 2020). Makerspaces are dynamic, loft-like spaces where children come with their teachers (and sometimes parents) to pursue their interest-driven making projects, share their design challenges, and work individually or collaboratively-often supported by adult facilitators (Gutwill et al., 2015). To that end, makerspaces provide a wide variety of traditional and digital fabrication tools, materials, and resources for supporting maker-centred learning (Gutwill et al., 2015). The emergence of a maker culture has resulted in an increase in makerspaces in schools, libraries, and other informal learning environments (Halverson \& Sheridan, 2014; Jaatinen \& Lindfors, 2020). In many countries, maker-centred learning usually takes place during afterschool clubs rather than in school (Halverson \& Sheridan, 2014; Kafai \& Peppler, 2011), but an educational maker culture has resulted in makerspaces being established in schools or school libraries. Finland has, however, a long tradition of craft education; it is a compulsory school subject for students in grades 1-7 and an optional one in grades 8-9. Consequently, our country has its own educational maker culture in terms of all schools having makerspaces in the form of craft classrooms (Jaatinen \& Lindfors, 2020), where various multi-material (metal, textile, wood) maker activities have been pursued for almost 150 years. The emergence of digital fabrication has expanded the scope of such innovation activities considerably (Riikonen et al., 2020; Sinervo et al., 2020). Craft education covers various textile and technical skills and techniques, together with emphasising designing, problolving, and craft expression. Maker-centred learning engages students in externalising their ideas through conceptual (spoken or written ideas), visual (drawings, sketches), or material (3D prototypes and models) artefacts, creating an opportunity for themselves and their peers to build on these ideas, discuss and elaborate upon them, and embody such ideas in more advanced artefacts (Mehto et al., 2020). Besides traditional tools and techniques, the use of microcontrollers (e.g. Picaxe; Micro:bit), sensors, robotics (e.g. Lego EV3), 3D printing, and, recently, also e-textiles has become a part of craft education in Finnish schools (Korhonen \& Lavonen, 2017; Seitamaa-Hakkarainen \& Hakkarainen, 2017).

\section{The cross-age peer tutoring approach}

Willis and colleagues (2012) defined tutoring as a platform for providing young people with social support, giving goal-oriented academic assistance, and, when appropriate, promoting positive identity development. The rationale of peer tutoring is often anchored in the concept of the zone of proximal development (ZPD; Vygotsky, 1978), representing the distance between what a learner (tutee) can do independently and what he/she can do with the help of more knowledgeable others (tutor). Accordingly, it is critical to challenge learners to go beyond their prevailing knowledge and competences and to provide facilitating coaching and support through more knowledgeable and skilful peers and beyond that of teachers. After having themselves recently gone through similar learning challenges, the 
tutors are likely to relate to the tutees' cognitive challenges; this increases the pedagogic value of peer tutoring. As an adult expert may be too distant in terms of authority and knowledge, peer tutoring may enhance opportunities for mutual interaction between tutor and tutee, resulting in a more active role of the students (Willis et al., 2012). Same-age peer tutoring (e.g. more skilled students tutoring others at a certain grade level) is distinguished from cross-age peer tutoring, where older students tutor their younger peers (Duran \& Topping, 2017; Karcher, 2008; Topping et al., 2017). The competence gap should not be too extreme between the tutor and the tutee, suggesting that the optimum age gap in cross-age peer tutoring should not be more than two or three years (Karcher, 2008); in the present case, the age difference was only one year. Although peer tutoring is much less practised and studied at the elementary and secondary levels than in tertiary education (Morrison et al., 2000; Topping et al., 2017; Willis et al., 2012), it has a long history in school counselling (Karcher, 2005), and some tutoring programmes have been initiated in primary and secondary education (Karcher, 2008; Morrison et al., 2000). Further, peer tutoring has often focused on transmitting basic skills, such as reading, numeracy, and motoric performance, and on promoting positive educational attitudes (Topping et al., 2017). Nevertheless, very little is known about cross-age peer tutoring in the context of STEAM education in general and maker-centred learning in particular; the present investigation aims to fill this research gap.

Many successful cross-age peer tutoring programmes are highly structured and prescriptive in nature, in terms of relying on pre-planned learning activities and aiming at prespecified learning outcomes (Karcher, 2005), in accordance with the basic-skill focus of peer-tutoring pedagogies. In the present case, in contrast, cross-age peer tutoring took place in the context of an open-ended maker-centred learning project based on nonlinear pedagogy and emergent technology-mediated maker activities, which were novel for the tutees, tutors, and their teachers. Yet, students are often more familiar with the practical aspects of emerging digital technologies than their teachers; this challenges teachers' traditional authoritative role as the most knowledgeable members of a community and highlights the epistemic value of peer tutors. Although a tutor student may not have adult competences, he/she may function in an expert role (Mieg, 2013; Olson \& Bruner, 1996), answering questions and explaining various issues. Peer tutors may be seen as "experts by experience," who share their cultivated know-how with peers while simultaneously stretching their capabilities and learning novel skills and competences (Willis et al., 2012). Sustained participation in complex problem solving when seeking solutions to open-ended invention challenges encountered in guided maker projects is likely to facilitate the further development of a tutor student's knowledge and competence and allow for the sharing of valuable know-how with peers. "Learning by teaching" (Duran \& Topping, 2017) makes peer tutoring educationally valuable; it requires a significantly deeper level of understanding than mere individual learning. Accordingly, peer tutors are not only challenged by mastering technological aspects of making processes, but also have to learn basic instructional skills involved in teaching their peers and socially organising tutees' learning activities.

Moreover, peer tutoring entails adopting a new social role in a community and becoming a student expert who is able to provide relevant guidance for younger peers. Investigations by Barron and her colleagues (2009) indicated that students who become exceptionally skilful in using sociodigital technologies often have very strong informal social networks, ranging from supportive parents to extended networks of like-minded people on the internet. To effectively support younger students, peer tutors have to be able to function as a network and share and pool, advance, and apply their heterogeneously distributed knowledge and competences. When peer tutors become aware of their distributed epistemic resources and put deliberate effort into 
employing these resources, the network is likely to provide social capital (Lin, 2002) in terms of mutual trust, proactive peer assistance, and the integration of personal efforts. Hence, effective participation in peer tutoring requires the active building of personal social networks, which provide access to relevant knowledge, tools, and competences beyond a student's immediate friends (Nardi et al., 2000). As far as one's own knowledge and competence are fragile, functioning in a tutor's role is a socio-emotionally (Willis et al., 2012) and existentially (Packer \& Goicoechea, 2000) challenging experience; this highlights the importance of social networking support. Further, young people build their sense of capability by having their contributions socially recognised by the community (Honneth, 1995). Hence, participation in peer tutoring may not only foster competence development, but also strengthen a sense of belonging and of contributing to the community, thereby leading to enhanced self-efficacy (Bandura, 2006; Barron, 2004). Agentic efforts of learning, the building of new skills, and developing tutoring practices are likely to provide some actors with more central network positions than others. In the current study, we define "key tutors" as those who have a cognitively central role in providing advice to their peers and a brokering role in the overall peer-tutoring network. Productive participation in prosocial peer assistance and assuming "collective cognitive responsibility" (Scardamalia, 2002) in a joint activity, as well as developing trusted relationships with teachers, are also likely to provide a central network position. As far as we know, cross-age peer tutoring has not been formerly studied from the social networking perspective.

\section{Research questions}

The present investigation focused on examining cross-age peer tutoring in the context of integrative STEAM projects wherein digital fabrication and traditional technologies mediated students' collaborative team efforts of inventing artefacts. Students from a technology-focused class tutored peers in the grade below on the topics of coding and robotics. We were interested in how tutors experienced cross-age peer tutoring, what kinds of challenges they encountered while tutoring student teams, and how networks mediated the key tutors' cognitively central roles among peer tutors. The research questions are as follows:

(1) What kinds of skills, motivations, and challenges did students providing cross-age peer tutoring encounter? We were interested in both the personal resources and obstacles encountered by the peer tutors during the nonlinear making process.

(2) What kinds of mutual advice networks did peer tutors build to support their efforts of guiding learning-by-making processes? We wanted to examine how the participants shared their knowledge and competences and learned to function as a network.

(3) What kinds of personal learning networks did cognitively central "key tutors" have beyond school? Such networks appear to be critical for explaining the expert role they achieved in the tutoring of the maker process.

\section{Methods}

\section{Participants and setting}

The participants of the present investigation were grade 8 students $(n=15)$ from a technology-focused class who were taking part in tutoring their younger peers in the context of a 
maker-centred STEAM project. The investigation took place in a lower secondary school in the capital region of Finland. The school collaborated with academic investigators and a participatory teacher training network (link omitted for blind review) to implement a maker project in grade 7 classes $(n=70)$ for students aged 13-14 years old. Three of the tutee classes were standard, and one was a technology-focused class for which students were selected through an entrance examination. The project was the first implementation of a 3-year educational design experiment (Collins et al., 2004) aimed at iteratively developing pedagogies of learning by making (see Riikonen et al., 2020 for details). The school had developed some practices in relation to using older students as tutors. By taking part in the present study, the school aimed at creating a more systematic practice of cross-age peer tutoring.

Teams of 7th grade students were engaged in co-inventing complex artefacts by using digital fabrication and traditional technologies in an integrative study project. The co-invention challenge, co-configured between teachers and researchers, was as follows: "Invent a smart product or a smart garment by relying on traditional and digital fabrication technologies or other programmable devices or 3D CAD." The projects were started in February and involved eight to nine weekly sessions (90-135 min per session) during March, April, and May 2017. The students worked in co-invention teams throughout the project. As described by Riikonen et al. (2020), Riikonen et al. (2020)), the student teams developed the following co-inventions: (1) a three-wheel bike containing smart technologies, such as an environment responsive, rechargeable LED lighting system; (2) an MGG (mobile gaming grip)—a pair of handles that improves the ergonomics of a mobile phone while playing games; (3) a smart outfit for sports, including an environment-responsive lighting system to improve safety; and (4) a smart insole for sport shoes, including an automatic warming system for winter sports. Most teams developed well-articulated design ideas, produced visualisations and prototypes, and tested and refined their co-inventions.

The present study began in fall 2016 when 6 student tutors were sent to a university to learn about the co-invention projects and start planning the implementation of peer tutoring. In February 2017, researchers gave all the tutors $2 \mathrm{~h}$ of training in using the GoGo Board programming tool. This programming tool is an affordable and multi-faceted digital fabrication instrument based on a visual programming language; it involves a microprocessor and numerous robotic elements, such as sensors and actuators (e.g. electronic engines) (Sipitakiat et al., 2004). The GoGo Board was intended for use in several co-invention projects, and the tutors were encouraged to further explore the instrument. After the training, three student tutors (referred to by using the pseudonyms Joona, Lauri, and Elias) who indicated exceptional agency were asked to co-plan GoGo Board training for 7th grade students with slides and activating tasks. In February, one training session was organised for each of the four 7th grade classrooms. After the training sessions, the craft teacher invited a few tutors at a time to support the 7th graders with their co-invention projects. During the training sessions, 12 tutors worked in pairs supporting the student teams, while Joona, Lauri, and Elias functioned as organisers of the whole class activity. Four subject teachers representing craft and technology education, computer science, chemistry, and physics took part in the project at the target school. These teachers and two researchers, whose support was mentioned by students, were included in the present research data.

\section{Methods of data acquisition}

The data acquisition involved semi-structured interviews with the 15 peer tutors (Kvale \& Brikmann, 2009). The themes related to their tutoring experiences, personal interests, 
and experiences of developing sociodigital competences to help answer the first research question. To answer the second question, egocentric network interviews (Crossley et al., 2015; McCarty et al., 2019) were performed with the name generator method. Each tutor was asked to put his/her name (ego) in the middle of a large sheet of paper and, around his/ her name, indicate those networking partners (alters, i.e. other tutors, teachers, researchers) from whom they obtained assistance during the peer tutoring process. The third research question, in turn, was answered by asking each tutor to complement his/her personal network drawing with various kinds of knowledge, support, and resources that flowed across family, schoolmates, friends outside of school, and hobbies to support the development of digital competences. Although such data gathering involved all the tutors, we will only present two case studies in relation to the cognitively central key tutors. The interview and egocentric network data were collected after piloting in fall 2017. At the time of the interviews, the student tutors had delivered their training sessions to the 7th graders and had started supporting the co-invention project along with teachers. Table 1 presents a summary of the research data.

\section{Methods of data analysis}

The interviews addressed multi-faceted themes; for the purposes of the present study, those aspects of the interviews that were relevant for answering the present research questions were identified for qualitative analysis. The first research question on tutors' skills, motivations, and challenges was analysed through the qualitative analysis of the interview data (Saldaña, 2015) using Atlas.ti and by relying on a theory informed and data-driven approach. Guided by recent theories of learning and (student) expertise (Bransford et al., 2006; Hakkarainen et al., 2004; Markauskaite \& Goodyear, 2017), we focused on the interview data for identifying text segments wherein students' knowledge, competences, and agency involved in overcoming challenges were mentioned. The units of analysis consisted of thematically defined meaningful ideas (the smallest coherent meaningful idea), which varied from one to several sentences in length. During the first stage of analysis, we identified two main themes occurring in the tutors' interview talk: tutors' skills and motivation as superordinate categories. In the second stage, we clustered the identified text segments under the superordinate categories. The competences required by the tutoring experience were categorised into technological skills, teaching skills, social competences, self-regulative skills, and reflective skills; these skills were revealed as tutors talked about overcoming the various challenges encountered. Such expressions were included, for instance, in the application of technology and group management. An example of categorising the text segments with data excerpts relating to tutors' skills is presented in Table 2. The superordinate theme of motivation involved expressions in which tutors talked about their motivating and inspiring experiences with regard to tutoring. Under this subordinate theme, we identified several factors that fostered motivation and commitment, such as interest, social contribution, and peer activity. Interest was further subdivided into technology and teaching interests. Social contribution indicates a participant's pride in his/her independent role while being involved in the experience of helping others as separate from teacher guidance.

To answer the second research question, we examined tutors' advice networks by summarising the mentions that he/she had received in the egocentric network interviews regarding advice provided during the peer tutoring process; the teachers were also mentioned as having offered advice. In social networking terms, the advice size (Hakkarainen et al., 2004) represents Freeman's in-degree value of the advice network 
Table 1 A summary of the participants and the research data

\begin{tabular}{|c|c|c|c|c|c|}
\hline Name & Gender & Advice size ${ }^{a}$ & Role in tutoring & $\begin{array}{l}\text { Length of inter- } \\
\text { view (min.) }\end{array}$ & $\begin{array}{l}\text { Length of } \\
\text { interview } \\
\text { (words) }\end{array}$ \\
\hline Aulis & Male & 0 & Tutor & 37 & 4605 \\
\hline Elias & Male & 5 & Key tutor & 52 & 6807 \\
\hline Janne & Male & 0 & Tutor & 43 & 4547 \\
\hline Joona & Male & 10 & Key tutor & 43 & 6320 \\
\hline Juuso & Male & 0 & Tutor & 37 & 2766 \\
\hline Lauri & Male & 11 & Key tutor & 45 & 4286 \\
\hline Leo & Male & 0 & Tutor & 29 & 2757 \\
\hline Luka & Male & 1 & Tutor & 34 & 3867 \\
\hline Mikko & Male & 0 & Tutor & 36 & 3809 \\
\hline Otto & Male & 1 & Tutor & 46 & 6274 \\
\hline Petri & Male & 0 & Tutor & 40 & 3071 \\
\hline Sami & Male & 0 & Tutor & 34 & 3701 \\
\hline Santeri & Male & 1 & Tutor & 26 & 3796 \\
\hline Katri & Female & 1 & Tutor & 36 & 3922 \\
\hline Minna & Female & 1 & Tutor & 38 & 5211 \\
\hline Paula & Female & 5 & Computer Science teacher & - & - \\
\hline Leila & Female & 5 & Craft teacher & - & - \\
\hline Jouko & Male & 3 & Craft teacher & - & - \\
\hline Hannu & Male & 2 & Physics teacher & - & - \\
\hline Seija & Female & 2 & Researcher & - & - \\
\hline Karita & Female & 1 & Researcher & - & - \\
\hline
\end{tabular}

a denotes the advice size

Advice size indicates the number of students who reported asking for advice from the given participant; advice size socially validated the key tutoring role

Teachers and researchers did not construct an egocentric network map, so their advice size was determined by relying on in-degree values based on peer tutors' nominations

(the number of links coming from community members who acknowledge receiving pieces of advice from participants). Consequently, it is not based on self-reporting but instead the social recognition of the whole community regarding a person's role in providing valuable advice. Hence, it provides a socially validated measure of a tutor's cognitive centrality in the peer tutoring process. We created an Excel matrix regarding indegrees of the provided advice network and used the CytoScape program (https://cytos cape.org/) to construct a network map of the tutor network.

This stays in the method section of the third research question, we examined two key tutors' egocentric networks, in which Lauri acted more as a technology expert and Joona occupied more of a social organiser role. They had exceptionally large advice sizes as well as important network brokerage roles in the peer tutoring process. The interview data assisted in examining their networking activities as well as the ecologies of sociodigital learning extending beyond the school. Both the semi-structured 


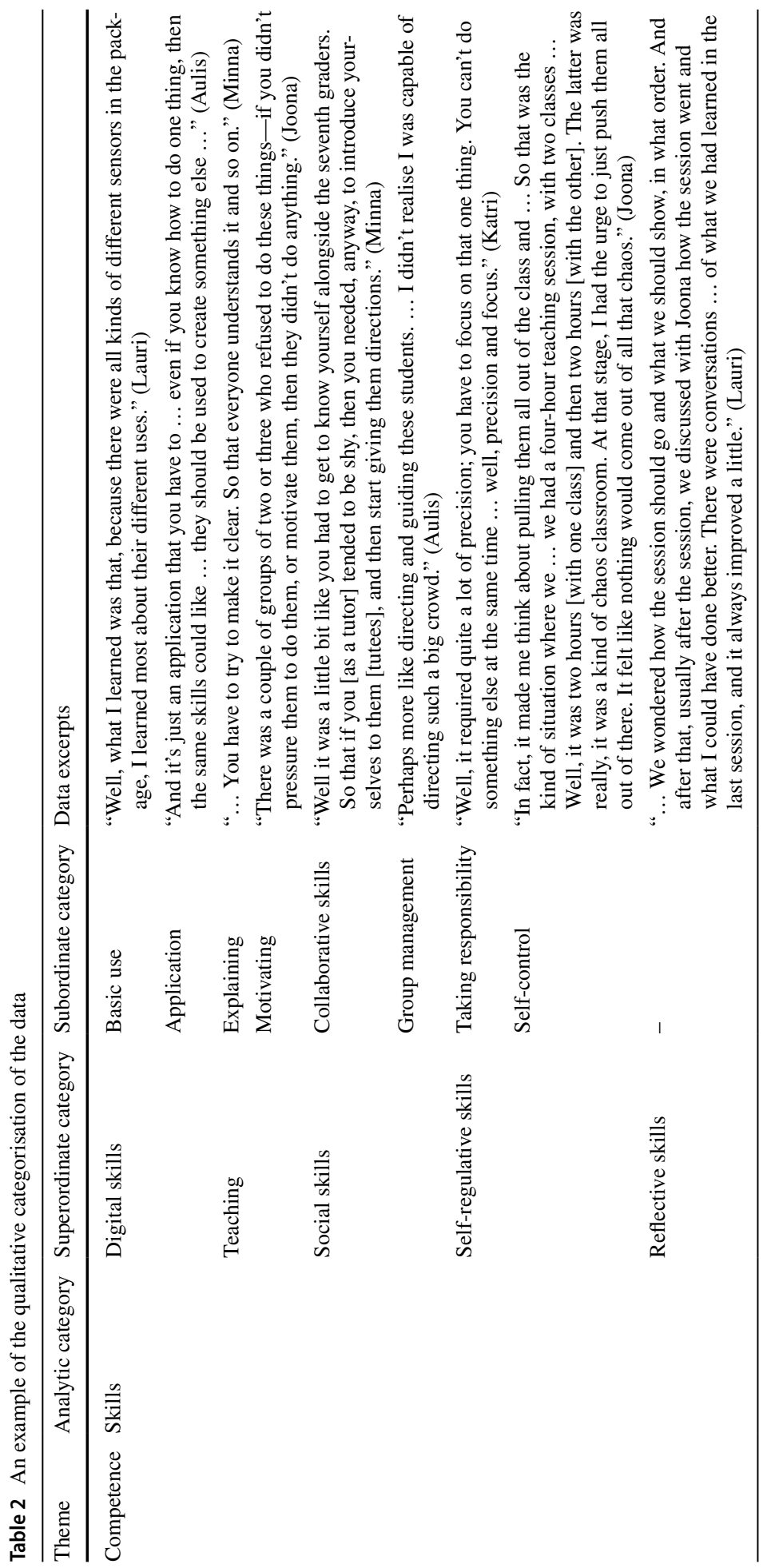


Fig. 1 Advice network of the present peer tutoring project. The network map includes tutors $(\mathrm{T})$, teachers $(\mathrm{O})$, and researchers $(\mathrm{C})$. The arrows represent the relationships between actors related to giving and receiving help (the direction of an arrow goes from the advisor to the person asking for advice). These relations were either one-directional or bidirectional. When interpreting the figure, the fact that information was only collected from tutors (who mentioned teachers and researchers as providers of help) should be taken into consideration

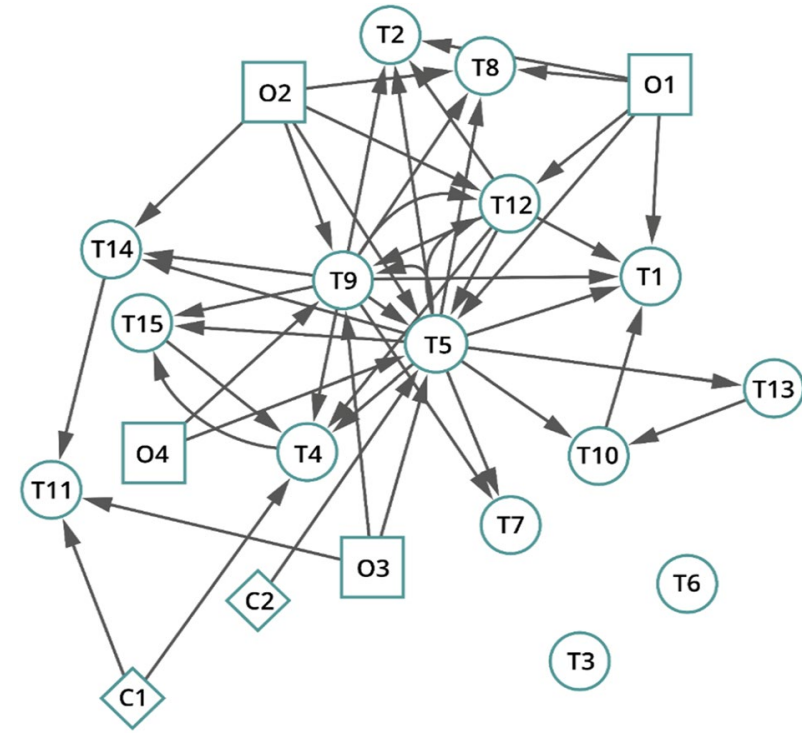

interviews and egocentric network data helped create rich descriptions of the key tutors' learning networks.

\section{Results}

\section{Peer tutors' experienced competences and motivation}

The first research question focused on the competences and motivation that peer tutors experienced as necessary for overcoming challenges encountered in the tutoring process. In the present project, the tutors' role was, first, to help tutees learn to productively utilise the GoGo Board in their co-invention projects. Second, some of the tutors were also later asked to guide the tutees in their co-invention projects by helping them with problem solving, troubleshooting, and further developing their ideas. Nevertheless, the tutors only received a two-hour training session themselves, which, reportedly, made their work very challenging. Despite this, the tutors described many skills that were learned and competences that were cultivated to overcome these challenges. These skills were categorised as technical skills, teaching skills, social skills, self-regulatory skills, and reflective skills.

One of the challenges experienced by tutors was uncertainty and confusion concerning the student teams' co-invention projects. The tutors were expected to guide the projects by not only providing tutees with technical guidance but also motivating them to start their first trials with the GoGo Board. Many of the tutors described their own trials of learning more with regard to using the tool; some felt frustrated because their technical competences were inadequate. Tutors talked about both basic skills in terms of understanding how the GoGo Board functions and advanced skills related to integrating several functions to design something that works with the GoGo Board. The tutors also appeared to have a realistic view of their own skill levels and knew whom in the tutor group they could ask for help. However, the varying skill levels within the tutor group sometimes led to 
pressure being put on the more skilled tutors, who were rushed while assisting the many tutee groups. Further, the tutors experienced the need to have broader peer teaching skills, such as (a) abilities in terms of explaining how the GoGo Board works and (b) the capability to motivate the tutees to persist until any problems were solved.

And then just encourage, so like you can do it, maybe it will become something ... sometimes it doesn't work, in which case you have to keep encouraging so that they keep trying and don't give up. (Aulis).

The tutors worked as a group and, therefore, needed to cooperate with their fellow tutors. They also had to find ways to get to know their tutees because they did not yet know them personally. The tutors had to cooperate with different personalities and ways of working. Further, some of the tutors described the social challenges of tutoring and "leading" a co-invention group. While teaching, the tutors had the freedom to establish the activities and behavioural boundaries of situations; this was often challenging because the tutees did not want to obey fellow students. Some tutors were positively surprised that they managed to lead a group. Joona, however, described the stress of leading a tutor group where some of the tutees were disruptive or did not want to put their mobile phones away.

At one point, we had to threaten as a big group that we would be moving some of them to Leila's [the teacher's] class. We were thus able to get them to calm down, which was great. (Joona).

Some of the tutors described self-regulatory skills, which were clustered and named as taking responsibility and self-control. Elias, for example, described the importance of concentration and responsibility in allowing him to complete all his tasks. Self-control was necessary in situations that aroused emotions like frustration, and Petri, for example, described his way of solving a problem as "just walking away from the situation." Craft teacher Leila encouraged tutors to reflect on their experiences by writing notes after tutoring sessions. In these reflections, the tutors went through the teaching sessions, developed training tasks and evaluated them, and considered new ways of using the GoGo Board. In the following excerpt, Janne described a situation wherein he realised that their planned exercise was not working in a real-life situation:

We had had discussions about whether we could hold teaching moments, where we would personally teach them... for example, by giving them a mystery to solve, like how to get an instrument to work, and then put a timer on the screen with gradually accelerating beeping. So, at one point, we had a big teaching session with two classes of seventh graders and our own class so that ... there just were not enough people to guide everyone ... We also tried to keep some kind of guessing session. (Janne).

The data revealed that tutors who were interested and skilful in using technology also appeared to find tutoring interesting. Experience of gaming or programming was also described as a good basis for learning to use and understand the functions and possibilities of the GoGo Board. Those who lacked technological skill, but were interested in teaching, had more motivational challenges. However, almost all the tutors could name at least one positive, motivational, or rewarding experience regarding tutoring. Some of the tutors even shared that they became more interested in teaching during tutoring. Some tutors also had previous experiences of teaching others, and Janne, in turn, had an existing interest in a teaching career before tutoring. However, Joona mentioned that the challenging experiences of trying to make tutee groups work made him prefer teaching older age groups. 
Further, having an important role in the project appeared to provide tutors with $a$ sense of social contribution, which helped make the process a rewarding experience. In this regard, almost all the tutors talked positively or neutrally about the valuable experience of having an independent role in the project. Given that teachers' digital skills were experienced as being poorer than those of the tutors, as reported by Minna, it was natural to go about asking for help from fellow tutors instead of the teachers, thus highlighting their independence. The tutors seemed to accept and carry out their independent roles and expectations, mostly with good results and experiences. However, they also recognised the boundaries of their capabilities in terms of group leading and teaching. Yet, most of them did not question this responsibility:

Um, I don't think a teacher was available ... Most of them had their own lessons and you didn't always have somebody coming in to check on how it went, but ... I doubt most of the teachers could do anything; the idea was we'd teach it all. Yeah, it was close to being one of those, let's haul one of them to Leila's class. (Joona).

Another aspect of social contribution was helping others: almost all the tutors recognised their role as helpers who can assist others in learning new things. Minna, who experienced her digital skills as being inadequate and was not so interested in technology, described helping others as the most positive and meaningful part of tutoring. Moreover, tutors who considered the fellow tutors and tutees as friends talked about them as a positive and motivating asset.

Yeah. We were a tutor pair, and it was just nice because some of the tutees were actually his and my friends. It was like, exciting to know the person we were teaching. ... And then it was like ... I don't know ... it at least made it easier to teach when we already knew the person. But even when other groups came [for tutoring], we got along pretty well with cooperation, so we shared those tasks pretty well. (Aulis).

To summarise, the analysis indicated that when the tutors talked about their positive experiences and motivational assets, they mostly talked about personal interests and social contributions. This means that they are proud of their independent role and ability to help others. Fewer tutors mentioned friendships or variation from ordinary schoolwork, but these had a strong positive meaning for those tutors who did. A personal technology interest appeared to make tutoring easier, but an interest in teaching was sometimes experienced as conflicted because of the associated challenges of group management. Some tutors who were not particularly interested in technology enjoyed explaining and helping others, although they also shared that tutoring felt difficult and challenging at times.

\section{The advice network among the peer tutor group}

The second research question concerned the social network that mediated peer tutors' efforts to guide maker-centred learning, as well as the identification of cognitively central actors among the overall peer tutoring network, including teachers and researchers. Figure 1 presents the whole advice network of tutoring constructed with the help of the CytoScape program. The network includes 15 tutors, 4 teachers, and 2 researchers. The arrows in Fig. 1 represent the direction of help. As can be seen, the most active helpers have many arrows pointing towards them (they have been named as helpers by others); these represent the advice size (Table 1) and indicate how many other tutors named him/ her as a helper with regard to tutoring. When examining the most active tutors, it is also 
interesting to pay attention to the tutors who named many people who helped them. Three of the tutors seem to have worked as cognitively central actors, even more than the teachers. We call these key actors, [T5], [T9], and [T12], "key tutors," and they are located in the middle of the figure, mediating networking relations among the peer tutoring network. Only five tutors had bidirectional arrows between themselves and someone else (T9, T5, T12, T4, and T15). Although many tutors mentioned working closely together with their tutoring partners, they did not always mention their partners when asked who had helped them; perhaps "helping" was understood as receiving help from a more competent or capable peer. Those five tutors who had the bidirectional arrows seem to have worked very closely together with someone with similar capabilities, but also named them as helpers, maybe in a more cooperative sense. Although some other tutors were close to the key tutors, most of them had received rather than provided pieces of advice. Meanwhile, some tutors appeared as isolates, indicating a passive role in the peer tutoring process (Fig. 1).

Two of the teachers $[\mathrm{O} 1=$ Paula and $\mathrm{O} 2=$ Leila $]$ received the highest number of mentions by tutors as helpers. Yet, these teachers did not have a very high advice size rating. All three key tutors and two other tutors mentioned a craft teacher [O2], who coordinated the project and orchestrated the tutors' work. Two of the key tutors and three others mentioned [O1], the computer science teacher. These two teachers provided significant help for both the key tutors and other tutors. The physics and chemistry teacher [O4=Hannu] and a craft teacher $[\mathrm{O} 3=$ Jouko] were only named as helpers by the key tutors; they appeared to have only provided background help for the key tutors. Many tutors did not mention the researcher $[\mathrm{C} 1=$ Karita $]$ who introduced the GoGo Board to them in a 2-hour workshop. This might be because the workshop was held long before the interviews or because of the short duration of the workshop and the formal training for the tutors. [T5] also mentioned a research team member $[\mathrm{C} 2=$ Seija $]$, who was a participant observer in the classroom during the tutoring process.

\section{The personal social networks of the key tutors}

The third research question focused on examining the key tutors' personal social networks beyond school. We were interested in examining what kind of ecology of sociodigital learning the key tutors had and what kinds of resources their networks provided. Next, we will describe two of the three key tutors' egocentric networks. The students had notably different profiles. While Lauri represented expertise in digital technology, together with the excluded key tutor, Elias, Joona filled a very central social role. The broader social network and sociodigital technology learning ecology of these two tutors will be described in this part of the paper.

\section{Lauri's personal social network}

Lauri's egocentric network (Fig. 2) consisted of four groups: family members, two different peer groups, and a tutoring group. The first group of peers was a group of friends with whom Lauri casually hangs out, talks about politics, and plays some sports. With this group, Lauri does not usually do many technology-based activities but might casually play a computer game. Lauri also interacts with a peer computer group of five boys who participate in gaming or programming activities. Two peers [T5K1 and T5K2] in the group provide help when problems concerning programming or digital devices are encountered. 
Fig. 2 Lauri's (T5) personal social network. Joona (T9) was mentioned twice because he was considered both a friend and a fellow peer tutor

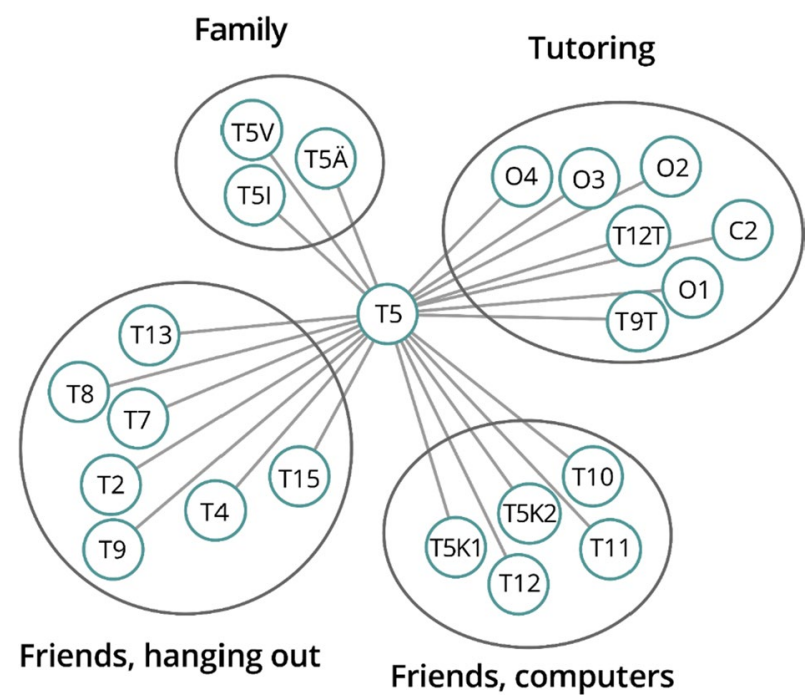

As a tutor, Lauri was highly independent and enthusiastic. After the introduction workshop for the GoGo Board, he wanted to learn more about the device and kept practising and performing trials. His technological capabilities, such as programming, were already extensive when the peer tutoring process began. Other tutors described Lauri as a resourceful helper and as a capable programmer who coordinated and guided the group alongside another key tutor, Joona. Lauri concretely described the assistance that the four teachers provided him with: Paula (O1) helped to create a PowerPoint presentation, Leila $(\mathrm{O} 2)$ helped to organise the project and provided knowledge about textile materials, Jouko (O3) helped with the technical side of making prototypes, and Hannu (O4) helped with new ideas and designs. Researcher Karita (C1) taught him to use the Arduino-based Flora e-textile device, which was required by some of the co-invention teams. Lauri reported extensive discussions with Joona and Elias about implementing the peer tutoring process throughout the whole project. Some of the discussions also concerned troubleshooting technologies needed for demonstrating the GoGo Board, such as the output voltage for the device. They frequently pondered how tutoring could be physically realised, designed training sessions, and, subsequently, reflected on improvements.

Um, well, after lessons when we had to tutor seventh graders at the start of their project, we wondered how the lesson was supposed to go and what we were supposed to show and in what order. And usually after the lesson, Joona and I wondered how the lesson went and what we could have done better. Those kinds of conversations. (Lauri).

Outside the tutoring context, Lauri showed an interest in technology, which had motivated him to participate in the technology class at the school. He was very satisfied with the technology projects that the school had recently organised, where he was able to use his skills and inspire others. Although Lauri's technological capabilities were highly sophisticated for his age, he described technology-related actions as a hobby, which he did only for fun. Lauri mentioned three family members, especially his father, who had played an important role in his digital interests. Lauri was at primary school when he 
received his first laptop as a gift from his grandparents. Later on, when it started slowing down, Lauri realised that it was cheaper to assemble a computer that would meet his desires; he later learned to build one with the help of his father. Lauri saw that he learned best by doing things himself. Teaching or guiding others was also familiar to Lauri: he had guided younger children in the Scouts and had also been a teacher in a Scratch-programming club in primary school.

\section{Joona's personal social network}

Joona's egocentric network (Fig. 3) consisted of four groups: family, a sports hobby group, friends from school, and friends from tutoring. He also mentioned his holiday home neighbour (T9K5) as a friend. Joona mostly hangs out with his friends from school, but they do not share any common hobbies or specific interests. Joona's sports hobby takes up most of his free time, so he also spends a lot of time with his friends there. Family is important for Joona, not only as people to spend leisure time with, but also in supporting his interest in mathematics and physics. Unlike Lauri and Elias, Joona does not consider digital technology to be his hobby or have a specific group of friends interested in computers.

As a tutor, Joona received support from Lauri and Elias in particular, with whom he worked and solved problems. Additionally, Joona appeared to be strongly engaged in the 7th graders' co-invention projects. Joona described his enthusiasm in working with the invention ideas, and he was curious to see how they progressed. Almost all the fellow tutors described him positively as an "omniscient" agent who had a profound knowledge and understanding of the relevant issues; consequently, his leadership role during the peer tutoring was unquestionable. Joona himself described his role as a coordinator and considered Elias and Lauri to have a higher level of competence in terms of programming and

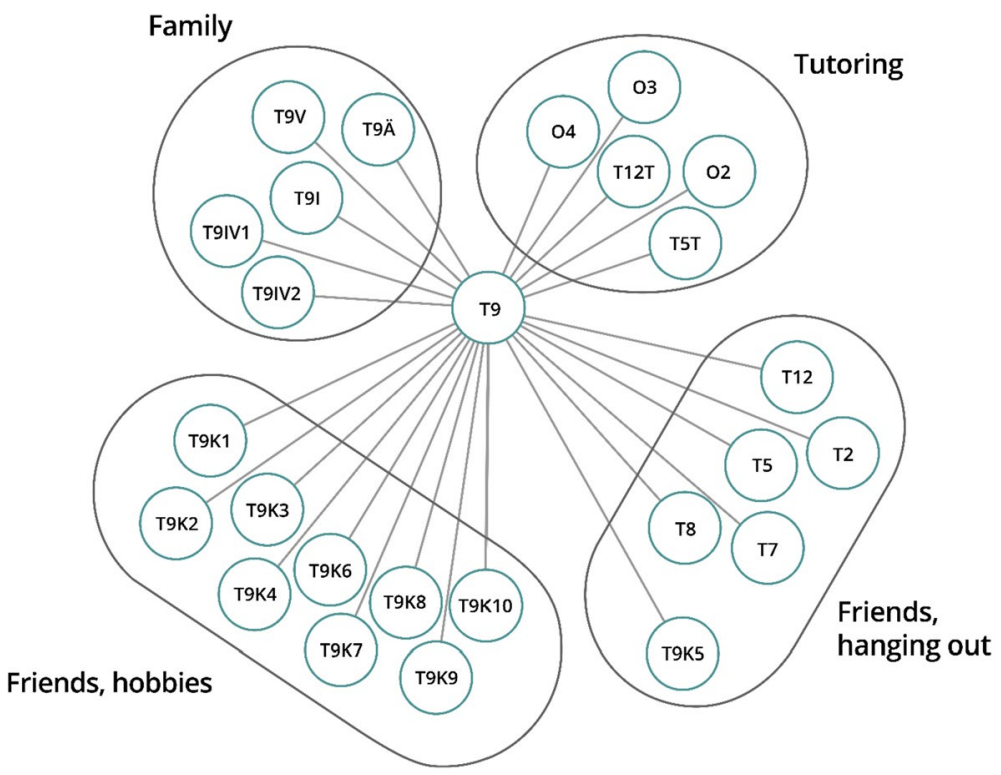

Fig. 3 Joona's (T9) personal social network. Lauri (T5) and Elias (T12) were mentioned twice because they represented both friends and fellow tutors 
computers. Like Lauri, Joona recognised the value of the expert network for the project and was able to identify the various expert roles of tutors and teachers. In the interview, Joona mentioned six tutors ("Who are the most interested in and somewhat know their way around computers?") who were given a central role in the tutoring project:

Well, I'm one of those who was probably the most enthusiastic about computers and doing very well in this regard ... After all, we were only six [tutors]. There was also Elias and Lauri, who were the ICT geniuses, so I kind of followed and coordinated the situations somehow. That is how I understood it. (Joona).

The co-operation between the three key tutors functioned well: "Mainly me, Lauri, and Elias are coordinating it, and they are funny guys [to work with]." Other tutors socially recognised the technological competence of Joona; this can be seen from his advice size within the tutor network (Fig. 1). Nevertheless, Joona himself did not think he was such an "IT-wizard" as Lauri and Elias. Instead, besides his sports hobby, his greatest interest was physics, which may be seen as closely related to computational thinking. Joona said that he spent some of his free time trying to solve physics problems and that his parents supported his associated activities. Further, the physics and chemistry teacher at the school, Hannu (O4), had an important mentoring role, giving ideas for problem solving and encouraging Joona to deepen his thinking about mechanical systems:

Well, then what was so great was that Hannu began explaining something [a technological innovation] that could be built on Mars, after you will get there, you could build that pipe [for transportation] ... if there is not [air) pressure, no air resistance, there is nothing; it's a vacuum. And then you could construct such a train. It would travel magnetically without any air resistance, allowing it to travel at an ungodly pace, which made me interested in at what speed it could go and how long it would last to go around Mars. And then I asked Hannu, and he just asked me to calculate it. He gave me a few formulas, and I worked out the rest of ... (Joona).

Although Lauri and Joona had somewhat different profiles regarding their interests, they both had a cognitively central role in the peer tutoring project, utilising complementary competences. Later on, the three tutors visited the university to present at various events, and they also trained teachers from other schools in the use of the GoGo Board. Tutoring continued after the present study, so that the current 7th graders who were selected for the 8th grade technology class became peer tutors, and the key tutors took part in the project's redesign.

\section{Discussion}

The present investigation focused on examining cross-age peer tutoring in the context of STEAM education. The study aimed at cultivating the creative use of technologies, within the context of a technology-enhanced maker project at a Finnish lower-secondary school. All the students from an 8th grade technology class functioned as peer tutors in coding and robotics for 7 th grade students whose maker teams worked to create complex artefacts with digital and material features. The study relied on the qualitative analysis of 15 semistructured interviews with the peer tutors as well as on ego-centric network analyses of the tutors' personal social networks within and beyond school. The ego-centric network 
data enabled the identification of socially validated key tutors whose networking patterns were described through two case descriptions. A limitation of the study was that the peer tutors interviewed come from one particular school that had developed its own tradition of peer tutoring; the results cannot straightforwardly generalized across other schools. Yet, the interview data provided content rich material of the tutors' multi-faceted experiences of fostering maker projects of their younger peers. Because the present study focused on examining cross-age peer tutoring, we did not examine student teams' making processes in details (see, however, Mehto et al., 2020; Riikonen et al., 2020; Riikonen et al., 2020for multifaceted analyses of student teams' making processes and inventions).

The first research question addressed the skills and motivations that the tutors needed to overcome the challenges encountered. The tutors realised that they needed a much wider set of competences than initially assumed and talked about intertwined technological, pedagogical, social, and reflective skills. The personal mastery of all these skills was not necessary because they all worked together. The tutors did not receive extensive training, and, therefore, their earlier experience of programming and using computers played an important role. Although technical competences were considered crucial, many tutors highlighted the importance of social and self-regulation skills, which they reportedly developed through tutoring situations. Some of them referred anonymously to fellow tutors who did not succeed in assuming social responsibility or managing the challenges of organising activities. A personal interest in digital technology emerged as the most important factor for enhancing a sense of meaningfulness during the tutoring project. Interest in teaching and guidance sometimes aroused conflicting feelings if the tutor experienced his or her own digital competence to be limited. Regarding the nature of the project, the most valuable experiences appeared to be providing tutors an autonomous or independent role as well as getting a sense of social contribution from engaging in prosocial helping others.

The second research question focused on the social networks that peer tutors created for supporting maker-centred learning. The results revealed that the cognitively central actors in peer tutoring were Lauri, Joona, and Elias, as estimated and socially validated through advice size. These key tutors appeared to have a brokering position between the 7 th grade students, other tutors, and the teachers and researchers. The other tutors asked for pieces of advice from the key tutors, whereas the key tutors received support from one another as well as from the teachers and the researchers. Hence, the key tutors acted as companions for teachers, they had deeper knowledge than others (teachers included), and they also organised the work of the tutor group.

The third research question examined the nature of the two key tutors' personal social networks beyond school. Both the key tutors had an interest they were excited about and were committed to improving their related competences. Their networks beyond school appeared to provide, in this regard, essential material resources (equipment), shared expertise within a family, social support from family, networks of friends interested in similar issues, and trusted and supportive teachers (Barron et al., 2009). Both key tutors reported developing their digital competences independently, yet without the feeling of being alone. However, the analysis of their backgrounds reveals that none of them functioned alone. They appeared as skilful network builders in terms of relationally recognising fellow tutors' skills and competences and distributing tasks and responsibilities accordingly. Further, they had been earlier recognised as active and tech-savvy students in the school context and had earned responsibilities and network connections in previous technology projects at school. The performance of the whole tutor group appeared to rely on the key tutors, their special expertise, and their capabilities of productively collaborating with teachers. 
Investigations have revealed the challenges related to providing both technological and pedagogical facilitation in makerspaces in schools (Gutwill et al., 2015). The present longterm co-invention projects were open-ended and nonlinear in nature and, consequently, did not only involve using GoGo Board, which was unfamiliar to all the tutors and teachers, but also the unforeseen use of even more complex Arduino-based instruments. The peer tutors' exceptional commitment for exploring and learning these technologies and using the emerging knowhow for scaffolding their younger peers' making processes played a crucial role in completion of the invention challenges. Simultaneously, the participants experienced the tutoring process to be pretty challenging. The challenges mentioned were related to (a) tutors' limited knowledge and competences (i.e. insufficient time for learning the required digital technologies well), (b) challenges of managing group dynamics, (c) limitations regarding designing the training for younger students, and (d) constraining features of the digital technologies used in the maker projects. Some of the challenges remained unsolvable and resulted in half of the peer tutors giving critical feedback regarding the organisation of the project.

The present investigation contributed to revealing the potentials of cross-age peer tutoring for STEAM education in general and maker-centred learning in particular. Over the last three years, we have developed a sustained cross-age peer tutoring system in integrated projects of design and technology education with the help of the student tutors. In the present case, the key tutors' coordinating team was highly dedicated to developing the tutoring system for the next iteration. Specifically, they took responsibility for recruiting and educating the next cohort of tutors: they selected six students from the first groups they had taught (7th graders who progressed to the 8 th grade), and they started teaching them more about the platforms and guided them on how to teach classes together with the coordinating team. Gradually, during spring 2018, the coordinating team stepped back and gave the new tutors more space to learn and be involved in the co-invention projects. During the subsequent iterations, the peer tutors will be selected from among students who have themselves completed a co-invention project; that will help tutors to relate to experiences of tutees struggling to overcome various challenges. Our experiences indicate that well-organized cross-age tutoring system provides significant support for teachers' and researchers' efforts of orchestrating challenging makercentred learning at school. Authentic maker projects tend to be heterogeneous and rely on multifaceted tools and practices that may be hard for teachers to master. Peer tutors' support and facilitation tailored according to each maker project's needs appear to play an important role in successful completion of the making processes.

Functioning as peer tutors both challenges and fosters the development of their self-efficacy and self-image (Willis et al., 2012) the interviewees reported how functioning in the tutor role aroused uncertainty regarding one's role. Simultaneously, functioning in a role of student expert was considered motivating; despite the varying levels of competence or the intensity of activity, all tutors had a positive experience of prosocially helping others and a sense of contributing to the school community (Honneth, 1995). As a pedagogical practice, cross-age peer tutoring appeared to have fostered many tutors' personal and shared agency, especially that of those who were validated as the "key tutors." On the one hand, while previous investigations have revealed that young people are capable of the creative use of technology (Ito et al., 2009) in an informal learning context, the present study indicated, in turn, that technologically competent young people are able to productively guide and coach such creative processes. On the other hand, most of the peer tutors desired more structured and better supported peer-tutoring processes; this observation is also supported by an earlier tutoring investigation (Karcher, 2008; Willis et al., 2012). Such an approach could support a more democratic distribution of cognitive responsibility in the peer tutoring process at the level of the whole peer tutor community. 


\section{Conclusion}

The pursuit of maker-centred learning calls for nonlinear pedagogy that involves engaging teams of students in creating unforeseen creative solutions for ill-defined, authentic, and complex challenges (Viilo et al., 2011). Maker-centred learning represents a very promising approach on integrative STEAM education fostering creative use of digital technologies. Productive participation in a making project entails that student teams have to learn to productively deal with repeated failures. Simultaneously, orchestrating making processes is also likely to be challenging for teachers, who must be able to fluently adapt to emergent ideas, unfamiliar technologies, unforeseen epistemic needs, and unpredictable events and actions (Härkki et al., 2020). The contribution of the present investigation is to show that cross-age peer tutoring provides valuable support for teachers' and schools' for implementing innovative maker pedagogies. Peer tutors appeared to provide expanded resources for scaffolding student teams' maker projects and potentially enable utilizing more diverse technologies and coming up with more advanced digital solutions than would otherwise be possible.

Peer tutoring and other pedagogical frameworks that provide learners with an opportunity to function in the role of guide, mentor, or teacher appear to expand alongside pedagogical solutions for integrating the creative use of digital technologies with learning, teaching, and schooling. The systematic development of peer tutoring pedagogies appears to have a strategic role in helping students to become committed to learning and to participating in education activities as well as to finding novel agentic learning powers that do not yet have a legitimate position in schools. A significant proportion of young people have impressive sociodigital skills that could provide valuable social learning resources when their use is legitimised through peer tutoring practices. Yet, we are only at the beginning of systematically developing peer tutoring pedagogies in STEAM contexts and providing young people with opportunities to occupy expansive roles as tutors in contexts involving social learning pedagogies. Thus, the results of this study can provide a basis for future empirical STEAM research and pedagogical experiments that consist of or combine peer tutoring, technology education, and design research aimed at creating innovative technology-mediated learning environments.

Funding Open access funding provided by University of Helsinki including Helsinki University Central Hospital. This work was supported by the Academy of Finland Grant 286837 (Co4-Lab) and Strategic Research Council Grant 312527 (Growing Mind). The opinions expressed herein are those of the authors and do not represent the views of the funding agencies.

Open Access This article is licensed under a Creative Commons Attribution 4.0 International License, which permits use, sharing, adaptation, distribution and reproduction in any medium or format, as long as you give appropriate credit to the original author(s) and the source, provide a link to the Creative Commons licence, and indicate if changes were made. The images or other third party material in this article are included in the article's Creative Commons licence, unless indicated otherwise in a credit line to the material. If material is not included in the article's Creative Commons licence and your intended use is not permitted by statutory regulation or exceeds the permitted use, you will need to obtain permission directly from the copyright holder. To view a copy of this licence, visit http://creativecommons.org/licenses/by/4.0/. 


\section{References}

Bandura, A. (2006). Toward a psychology of human agency. Perspectives on Psychological Science, 1(2), 164-180

Barron, B. (2004). Learning ecologies for technological fluency: Gender and experience differences. Journal of Educational Computing Research, 31(1), 1-36

Barron, B., Martin, C. K., Takeuchi, L., \& Fithian, R. (2009). Parents as learning partners in the development of technological fluency. International Journal of Learning and Media, 1(2), 55-77

Binkley, M., Erstad, O., Herman, J., Ripley, M., Miller-Ricci, M., \& Rumble, M. (2012). Defining twentyfirst century skills. In E. Care, P. Griffin, \& B. McGaw (Eds.), Assessment and teaching of 21 st century skills (pp. 17-66). Springer.

Blikstein, P. (2013). Digital fabrication and "making" in education. The democratization of innovation. In J. Walter-Herrmann \& C. Buching (Eds.), FabLab: of machines, makers, and inventors. (pp. 203-222). Transcript.

Bransford, J., Stevens, R., Schwartz, D., Meltzoff, A., Pea, R., Roschelle, J., Vye, N., Kuhl, P., Bell, P., Barron, B., Reeves, B., \& Sabelli, N. (2006). Learning theories and education: Toward a decade of synergy. In P. Alexander \& P. Winne (Eds.), Handbook of educational psychology. (pp. 209-244). Erlbaum.

Clapp, E. P., Ross, J., Ryan, J. O., \& Tishman, S. (2016). Maker-centered learning: Empowering young people to shape their worlds. Jossey-Bass.

Collins, A., Joseph, D., \& Bielaczyk, K. (2004). Design research: Theoretical and methodological issues. The Journal of the Learning Sciences, 13(1), 15-42

Crossley, N., Bellotti, E., Edwards, G., Everett, M., Koskinen, J., \& Tranmer, M. (2015). Social network analysis for ego-nets. Sage.

Duran, D., \& Topping, K. (2017). Learning by teaching: Evidence-based strategies to enhance learning in the classroom. Routledge.

Gutwill, J., Hido, N., \& Sindoft, L. (2015). Research to practice: Observing learning in tinkering activities. Curator, 58(2), 151-168. https://doi.org/10.1111/cura.12105

Hakkarainen, K. (2009). A knowledge-practice perspective on technology-mediated learning. International Journal of Computer Supported Collaborative Learning, 4, 213-231

Hakkarainen, K., Hietajärvi, L., Alho, K., Lonka, K., \& Salmela-Aro, K. (2015). Socio-digital revolution: Digital natives versus digital immigrants. In J. D. Wright (Ed.), International encyclopedia of the social and behavioral sciences. (2nd ed., Vol. 22, pp. 918-923). Elsevier.

Hakkarainen, K., Palonen, T., Paavola, S., \& Lehtinen, E. (2004). Communities of networked expertise: Professional and educational perspectives. Elsevier.

Halverson, E., \& Sheridan, K. M. (2014). The maker movement in education. Harvard Education Review, 84(4), 495-504

Hatch, M. (2014). The maker movement manifesto. McGraw-Hill.

Hietajärvi, L., Lonka, K., Hakkarainen, K., Alho, K., \& Salmela-Aro, K. (2020). Are schools alienating digitally engaged students? Longitudinal relations between digital engagement and school engagement. Frontline Learning Research, 8, 33-55

Hogan, B., Carrasco, J. A., \& Wellman, B. (2007). Visualizing personal networks: Working with participant-aided sociograms. Field Methods, 19(2), 116-144

Honneth, A. (1995). The struggle for recognition. Polity.

Hsu, Y. C., Baldwin, S., \& Ching, Y. H. (2017). Learning through making and maker education. TechTrends, 61(6), 589-594. https://doi.org/10.1007/s11528-017-0172-6.

Härkki, T., Vartiainen, H., Seitamaa-Hakkarainen, P., \& Hakkarainen, K. (2020). Co-teaching in nonlinear projects: A contextualized model of co-teaching to support educational change. Teaching and Teacher Education, 97, 103188

Ito, M., Baumer, S., Bittandi, M., Boud, D., Cody, R., Stephenson, B. H., Horst, H. A., Lange, P. G., Mahendran, D., Martínez, K. Z., Pascoe, C. J., Perkel, D., Robinson, L., Sims, C., \& Tripp, L. (2009). Hanging out, messing around, and geeking out. The MIT Press.

Ito, M., Gutiérrez, K., Livingstone, S., Penuel, W., Rhodes, J., Salen, K., Schor, J., Sefton-Green, J., \& Watkins, S. (2013). Connected learning: An agenda for research and design. Digital Media and Learning Research Hub.

Jaatinen, J., \& Lindfors, E. (2020). Makerspaces for pedagogical innovation processes: How Finnish comprehensive schools create spaces for makers. Design and Technology Education: An International Journal, 24(2), 42-66

Jenkins, H., Clinton, R., Purushotma, R., Robinson, A. J., \& Weigel, M. (2006). Confronting the challenges of participatory culture: Media education for the 21st century. MacArthur Foundation. 
Kafai, Y. B., \& Peppler, K. (2011). Youth, technology, and DIY: Developing participatory competencies in creative media production. Review of Research in Education, 35(1), 89-119. https://doi.org/10. 3102/0091732X10383211

Karcher, M. J. (2005). Cross-age peer mentoring. In D. L. DuBois \& M. J. Karcher (Eds.), Handbook of youth mentoring. (pp. 266-285). Sage.

Karcher, M. J. (2008). The cross-age mentoring program: A developmental intervention for promoting students' connectedness across grade level. Professional School Counseling, 12(2), 137-143

Knorr Cetina, K. (1999). Epistemic cultures: How the sciences make knowledge. Harvard University Press.

Korhonen, T., \& Lavonen, J. (2017). A new wave of learning in Finland get started with innovation. In S. Choo, D. Sawch, A. Villanueva, \& R. Vinz (Eds.), Educating for the 21 st century perspectives, policies and practices from around the world. (pp. 447-467). Springer.

Kvale, S., \& Brikmann, S. (2009). Interviews: Learning the craft of qualitative research interviewing. (2nd ed.). Sage.

Lin, N. (2002). Social capital. Cambridge University Press.

Markauskaite, L., \& Goodyear, P. (2017). Epistemic fluency and professional education: Innovation, knowledgeable action, and actionable knowledge. Springer.

McCarty, C., Lubbers, M., Vacca, R., \& Molina, J. (2019). Conducting personal network research. Guilford.

Mehto, V., Riikonen, S., Hakkarainen, K., Kangas, K., \& Seitamaa-Hakkarainen, P. (2020). Epistemic roles of materiality within a collaborative invention project at a secondary school. The British Journal of Educational Technology, 51, 1246-1261

Mieg, H. A. (2013). Social and sociological factors in the development of expertise. In K. A. Ericsson, N. Charness, P. J. Feltovich, \& R. R. Hoffman (Eds.), The Cambridge handbook of expertise and expert performance. (pp. 743-760). Cambridge University Press.

Morrison, I., Everton, T., Rudduck, J., Cannie, J., \& Strommen, L. (2000). Pupils helping other pupils with their learning: Cross-age tutoring in a primary and secondary school. Mentoring \& Tutoring, $8(3), 187-200$

Nardi, B. A., Whittaker, S., \& Schwartz, H. (2000). It's not what you know, it's who you know: Work in the information age. First Monday. https://doi.org/10.5210/fm.v5i5.741

NCCBE. (2014). The Finnish National Board of Education. (2016). Perusopetuksen opetussuunnitelman perusteet 2014. [Finnish National Core Curriculum for Basic Education]. Retrieved from https://www. oph.fi/sites/default/files/documents/perusopetuksen_opetussuunnitelman_perusteet_2014.pdf.

Nersessian, N. (2006). The cognitive-cultural systems of the research laboratory. Organization Studies, 27, 125-145

Olson, D., \& Bruner, J. (1996). Folk psychology and folk pedagogy. In D. Olson \& N. Torrance (Eds.), The handbook of education and human development. (pp. 9-27). Blackwell.

Paavola, S., \& Hakkarainen, K. (2014). Trialogical approach for knowledge creation. In S.-C. Tan, H.-J. Jo, \& J. Yoe (Eds.), Knowledge creation in education. (pp. 53-72). Springer.

Packer, M., \& Goicoechea, J. (2000). Sociocultural and constructivist theories of learning: Ontology, not just epistemology. Educational Psychologist, 35(4), 227-241

Papavlasopoulou, S., Giannakos, M. N., \& Jaccheri, L. (2017). Empirical studies on the maker movement, a promising approach to learning: A literature review. Entertainment Computing, 18, 57-78

Papert, S. (1980). Mindstorms: Children, computers, and powerful ideas. Basic Books.

Petrich, M., Wilkinson, K., \& Bevan, B. (2013). It looks like fun, but are they learning? In M. Honey \& D. Kanter (Eds.), Design, make, play: Growing the next generation of STEM innovators. (pp. 50-70). Routledge.

Riikonen, S., Kangas, K., Kokko, S., Korhonen, T., Hakkarainen, K., \& Seitamaa-Hakkarainen, P. (2020). The development of pedagogical infrastructures in three cycles of maker-centered learning. Design and Technology Education: An International Journal, 25, 29-49

Riikonen, S., Seitamaa-Hakkarainen, P., \& Hakkarainen, K. (2020). Bringing maker practices to school: Tracing discursive and materially mediated aspects of student teams' collaborative making processes. Journal of Computer Supported Collaborative Learning, 15(3), 319-349

Ritella, G., \& Hakkarainen, K. (2012). Instrument genesis in technology mediated learning: From double stimulation to expansive knowledge practices. International Journal of Computer-Supported Collaborative Learning, 7, 239-258

Saldaña, J. (2015). The coding manual for qualitative researchers. Sage.

Schad, M., \& Jones, W. (2020). The maker movement and education: A systematic review of the literature. Journal of Research on Technology in Education, 52(1), 65-78 
Scardamalia, M. (2002). Collective cognitive responsibility for the advancement of knowledge. In B. Smith (Ed.), Liberal education in a knowledge society. (pp. 67-98). Open Court.

Seitamaa-Hakkarainen, P., \& Hakkarainen, K. (2017). Learning by making. In K. Peppler (Ed.), The SAGE encyclopedia of out-of-school learning. (pp. 421-424). Sage.

Silander, P., Riikonen, S., Seitamaa-Hakkarainen, P., \& Hakkarainen, K. (2020). Learning computational thinking in phenomenon-based co-creation projects: Perspectives from Finland. In S.-C. Kong \& H. Abelson (Eds.), Computational thinking education in K-12: Artificial intelligence literacy and physical computing. The MIT Press.

Sinervo, S., Sormunen, K., Kangas, K., Hakkarainen, K., Lavonen, J., Juuti, K., Korhonen, T., \& Seitamaa-Hakkarainen, P. (2020). Elementary school pupils' co-inventions: products and pupils' reflections on processes. International Journal of Technology Design and Education. https://doi.org/10. 1007/s10798-020-09577-y

Sipitakiat, A., Blikstein, P., \& Cavallo, D. P. (2004). GoGo Board: Augmenting programmable bricks for economically challenged audiences. In Y. B. Kafai, W. A. Sandoval, N. Enyedy, A. S. Nixon, \& F. Herrera (Eds.), International Conference of the Learning Sciences 2004: Embracing diversity in the learning sciences. (pp. 481-488). Erlbaum.

Topping, K., Buchs, C., Duran, D., \& van Keer, H. (2017). Effective peer learning: From principles to practical implementation. Routledge.

Vygotsky, L. S. (1978). Mind in society. Cambridge University Press.

Viilo, M., Seitamaa-Hakkarainen, P., \& Hakkarainen, K. (2011). Supporting the technology-enhanced collaborative inquiry and design project: A teacher's reflections on practices. Teachers and Teaching, Theory and Practice, 17(1), 51-72.

Willis, P., Bland, R., Manka, L., \& Craft, C. (2012). The ABC of peer mentoring: What secondary students have to say about cross-age peer mentoring in a regional Australian school. Educational Research and Evaluation: An International Journal on Theory and Practice, 18(2), 173-185

Publisher's Note Springer Nature remains neutral with regard to jurisdictional claims in published maps and institutional affiliations. 